\title{
Simple Rules That Guide Generalist and Specialist Care
}

\author{
Rebecca S. Etz, PhD; William L. Miller, MD, MA; Kurt C. Stange, MD, PhD
}

\begin{abstract}
The sometimes-paradoxical emergent behavior of complex systems may be explained by the interaction of simple rules. The paradox of primary care - that systems based on primary care have healthier populations, fewer health inequities, lower health care expenditures, and better system-level evidence-based disease care, despite less evidence-based care for individual diseases-may be explained by the iterative interaction among three simple rules that describe the generalist approach: (1) Recognize a broad range of problems/opportunities; (2) Prioritize attention and action with the intent of promoting health, healing, and connection; and (3) Personalize care based on the particulars of the individual or family in their local context. These are complemented by three simple rules for specialist care that represent current approaches to quality and health care system improvement: (1) Identify and classify disease for management; (2) Interpret through specialized knowledge; (3) Generate and carry out a management plan. Health care systems that support the enactment of the simple rules of the generalist approach are likely to have more effective primary and specialty care, and greater population health, equity, quality, and sustainable cost.
\end{abstract}

(Fam Med. 2021;53(8):697-700.)

doi: 10.22454/FamMed.2021.463594

\section{A Paradox}

Primary care, and its fullest manifestation as robust family medicine practice, is not simple. Integrating care for whole people and families may be the most complex task in health care, ${ }^{1}$ even if some of the entrée points involve seemingly simple tasks such as caring for self-limited or undifferentiated illness, ${ }^{2}$ identifying teachable moments for providing preventive services, ${ }^{3}$ or helping people to manage living with multiple chronic conditions..$^{4-6}$

Yet, in contrast to the whole-person focus that is its essence, primary care often is conceptualized, measured, and incentivized as merely the sum of many simple parts of care that can be well-captured by narrowly-focused, evidence-based guidelines ${ }^{7}$ that are based on highlyselected populations. ${ }^{8-11}$ Considerable investment and effort has gone into trying to incentivize and help primary care improve its disease-specific care, which most research finds to be less conforming to evidence-based guidelines than care provided by specialists in those diseases. ${ }^{12,13}$ However, incentivizing quality of care for the disease-specific parts of primary care has not yielded the hoped-for results. ${ }^{11,14,15}$

The paradox of primary care is that, despite providing less evidence-based care for individual diseases, systems based on primary care have healthier populations, less health inequities, lower health care expenditure, and better system-level, evidence-based disease care. ${ }^{16}$

Apparently there are emergent properties of primary care in which whole-person care is more than the sum of the parts of disease-specific care, and that provide added value to patients and populations. ${ }^{7}$ The purpose of this article is to explore how these emergent properties of primary care-manifested in the craft of generalist practice - might be understood, so that they can be supported, and how we might avoid the unintended consequence of fragmenting and reducing the whole of primary care by organizing around, incentivizing, and supporting only its component parts. ${ }^{11,17}$

\section{A Complexity Lens May Help}

Complex systems, in which nonlinear interactions result in hard-to-anticipate emergent properties, ${ }^{18}$ are an apt description of the generalist craft of primary care ${ }^{19-21}$ One of the most appealing (and most misunderstood) principles of complexity science

From the Larry A. Green Center (Drs Etz and Stange); Department of Family Medicine and Population Health, Virginia Commonwealth University, Richmond, VA (Dr Etz); Department of Family Medicine, Lehigh Valley Health Network, Allentown, PA (Dr Miller); Department of Family Medicine, University of South Florida Morsani College of Medicine, Tampa, FL (Dr Miller); Center for Community Health Integration, Cleveland, $\mathrm{OH}$ (Dr Stange); and Departments of Family Medicine \& Community Health, Population \& Quantitative Health Sciences, Oncology and Sociology, Case Western Reserve University, Cleveland, $\mathrm{OH}$ (Dr Stange). 
is that sometimes the behavior of complex systems can be described by simple rules. ${ }^{20,22,23}$ For example, the marvelously complex flocking behavior of birds can be produced by three simple rules: ${ }^{24}$

1. Align: line up with those close by;

2. Cohere: steer toward the emerging center mass of those around you;

3. Separate: seek to be equidistant from your neighbors so you don't collide.

\section{Simple Rules for Specialist Care}

The current conceptualization, organization, and measurement of health care is well described by the three simple rules of specialty care that work together in a fairly linear fashion:

- Identify and classify disease for management;

- Interpret through specialized knowledge;

- Generate and carry out a management plan.

Specialists are concerned primarily with identifying whether the patient has the disease(s) in which they are expert, and then applying that expertise in a focused way to diagnose and treat the disease of interest. This is a godsend for patients for whom particular knowledge or technical skill, developed by repeated focus on one thing, is needed. However, the unfettered application of specialist rules is less effective, more expensive, and potentially dangerous if applied unselectively without the contextualizing influence of generalists applying the generalist rules. ${ }^{25}$ And the application of specialist rules to the whole system, and in particular to primary care, is disastrous in leading to care that is fragmented, high cost, and low value. ${ }^{1,23,26}$

\section{Three Simple Rules for the Complexity of Primary Care}

The emergent properties of primary care are generated by the interaction, over time, among three simple rules that characterize the way of the generalist:

1. Recognize a broad range of problems/opportunities;

2. Prioritize attention and action with the intent of promoting health, healing, and connection;

3. Personalize care based on the particulars of the individual or family in their local context.

These rules work together as a set of linked feedback loops.

Recognizing requires foraging for salient information based on a comprehensive generalist perspective - teachable moments, early, often undifferentiated clues, risks and opportunities-in which any information potentially helpful to advancing health, healing, or relationship is relevant. ${ }^{2,27-30}$

Prioritizing may be the most underrecognized and unique function of primary care within the health care enterprise. ${ }^{31,32}$ It begins with the broad, inclusive generalist perspective, and requires sorting, ranking, and negotiating what is most important between the different experiential knowing and expertise of the patient, and that of the clinician, to identify what action has the greatest potential to advance health, healing, and connection. ${ }^{33,34}$

Personalizing care involves moving from the statistical generalities of evidence-based medicine to the particulars of this person or family in this particular moment and place and context. There are many particular moments within even a brief primary care encounter. And often, there are many encounters over time. ${ }^{28,34-38}$

These three simple rules interact in a nonlinear and highly iterative manner within and across encounters. ${ }^{39-42}$ They operate over and over again: (1) as new information reframes what problems or opportunities are recognized as salient; (2) as what is most important continually changes or is reinforced by each new recognition, hypotheses develop around what might be most useful in this encounter; (3) as the hypotheses are tried out with the intent of promoting some combination of health, healing, and/or connection. The cumulative effect of actualizing these rules is an investment in a relationship bank that can be drawn upon with interest during challenging moments in the health and lives of individuals, families, and communities. ${ }^{39,43,44}$

For example, a patient brings his grandson in for ear pain, fever, and runny nose. Their family physician recognizes the likelihood of an ear infection and after examination, makes that diagnosis. She prioritizes treating the acute illness, and personalizes care by prescribing a second-line antibiotic that only has to be given once a day, saving the family the hassle of taking the first-line antibiotic to and from day care. The physician also recognizes a teachable moment, and mentions to the grandfather, with whom she had long ago reached a truce about not nagging about his smoking, that having a smoker in the house doubles the risk of a child getting an ear infection. With this new, personalized motivation, they discuss a smoking cessation plan. This visit, still taking less than 10 minutes, prioritizes healing for the child, health promotion for the child and grandfather, and invests in connection with the family by sensitively meeting their immediate and longer-term need and opportunity.

\section{A Systems Approach}

In the complex, adaptive system of health care, ${ }^{45-47}$ the behaviors generated by these generalist and specialist simple rules are complementary. The generalist rules provide a broadly-inclusive entrée point into health care, and are an effective and efficient ongoing basis for providing and personalizing the majority of care. The generalist rules support engaging more narrow expertise when needed, and then integrating that targeted expertise back into coherent whole-person care. ${ }^{34}$

These rules are used by all clinicians. Specialist rules are the predominant approach of most 
specialists, and are used as one tool in the broader approach of most primary care generalists. Generalist rules are applied by specialists in some situations, but are the predominant approach of most generalists.

Specialist rules provide narrowlyfocused, deep expertise and technical skill/knowledge made more effective by strong primary care that filters out less relevant cases and allows specialists' narrow knowledge to be used with maximum benefit and minimum side effects from using often riskier treatments for which the benefits outweigh the risks. ${ }^{48}$ Generalist screening out or shared care of cases with complex multimorbidity makes the specialist population more like the highly-selected people who typically are included in clinical trials. ${ }^{8,49,50}$

The complementary nature of these rules help to explain the paradox that while generalists provide less evidence-based care of individual diseases than specialists in those diseases, locales that have a larger percentage of generalists exhibit better quality of disease care at the system and population level. ${ }^{51}$ The effect of the primary care rules in broadly recognizing, intentionally prioritizing, and integratively personalizing care may explain why health systems based on a strong primary care foundation have healthier populations, less inequity, and lower cost. ${ }^{16,52}$

The application of specialist rules is enhanced by vertically-integrated systems that organize multiple levels of care along disease-based service lines. ${ }^{53}$ The application of generalist rules is enhanced by horizontally integrated systems that organize cross-sectoral collaboration to improve overall health of people and populations. ${ }^{54,55} \mathrm{~A}$ whole-system approach in which vertical and horizontal integration develop in tune with each other, ${ }^{54,56}$ supports both specialists and generalists in doing what they do best and in advancing the emergent properties of healing and health for people and populations.

\section{Conclusion}

The exacting knowledge of specialism and the apparent simplicity and hidden complexity of generalism, both can be enhanced by knowing and supporting the actualization of their simple rules, together. The effectiveness of primary care practice and education can be enhanced by developing systems that support, rather than hinder, the integrative force of primary care and its broad focus and investment in relationships. ${ }^{1,16,57-60}$ Whole-systems approaches that recognize and promote an appropriate balance of specialized and generalist approaches, knowledge, and workforces, ${ }^{48,49}$ based on these apparently simple rules, have great potential to lead to the complexly-emergent outcomes of population health, equity, and health care quality at sustainable cost. ${ }^{61}$

FUNDING STATEMENT: This work is supported by grants from the University Suburban Health Center for the Wisdom of Practice Study, the American Board of Family Medicine Foundation, the Agency for Healthcare Research and Quality (1R13HS025312-01), Family Medicine for America's Health, the North American Primary Care Research Group, and by Virginia Commonwealth University and Case Western Reserve University.

CORRESPONDING AUTHOR: Address correspondence to Dr Kurt C. Stange, MD, PhD, Case Western Reserve University, 11000 Cedar Ave, Ste 402, Cleveland, OH 44106-7136. 216 368-6297. Fax: 216-368-4348. kcs@case.edu.

\section{References}

1. Stange KC. The problem of fragmentation and the need for integrative solutions. Ann Fam Med. 2009;7(2):100-103. doi:10.1370/afm.971

2. Heath I. The Mystery of General Practice. London: Nuffield Provincial Hospitals Trust; 1995.

3. Flocke SA, Clark E, Antognoli E, et al. Teachable moments for health behavior change and intermediate patient outcomes. Patient Educ Couns. 2014;96(1):43-49. doi:10.1016/j. pec.2014.03.014

4. Rijken M, Hujala A, van Ginneken E, Melchiorre MG, Groenewegen P, Schellevis F. Managing multimorbidity: profiles of integrated care approaches targeting people with multiple chronic conditions in Europe. Health Policy. 2018;122(1):44-52. doi:10.1016/j.healthpol.2017.10.002

5. Boult C, Wieland GD. Comprehensive primary care for older patients with multiple chronic conditions: "Nobody rushes you through". JAMA. 2010;304(17):1936-1943. doi:10.1001/ jama.2010.1623
6. Bayliss EA, Bonds DE, Boyd CM, et al. Understanding the context of health for persons with multiple chronic conditions: moving from what is the matter to what matters. Ann Fam Med. 2014;12(3):260-269. doi:10.1370/afm.1643

7. Stange KC. The paradox of the parts and the whole in understanding and improving general practice. Int J Qual Health Care. 2002;14(4):267-268. doi:10.1093/intqhc/14.4.267

8. Fortin M, Dionne J, Pinho G, Gignac J, Almirall J, Lapointe L. Randomized controlled trials: do they have external validity for patients with multiple comorbidities? Ann Fam Med. 2006;4(2):104-108. doi:10.1370/afm.516

9. Geyman JP. Evidence-based medicine in primary care: an overview. J Am Board Fam Pract. 1998;11(1):46-56. doi:10.3122/1557262511-1-46

10. Greenhalgh T. Why do we always end up here? Evidence-based medicine's conceptual cul-desacs and some off-road alternative routes. J Prim Health Care. 2012;4(2):92-97. doi:10.1071/ HC12092

11. Casalino LP. The unintended consequences of measuring quality on the quality of medical care. N Engl J Med. 1999;341(15):1147-1150. doi:10.1056/NEJM199910073411511

12. Smetana GW, Landon BE, Bindman AB, et al. A comparison of outcomes resulting from generalist vs specialist care for a single discrete medical condition: a systematic review and methodologic critique. Arch Intern Med. 2007;167(1):10-20. doi:10.1001/ archinte.167.1.10

13. Harrold LR, Field TS, Gurwitz JH. Knowledge, patterns of care, and outcomes of care for generalists and specialists. J Gen Intern Med. 1999;14(8):499-511. doi:10.1046/j.15251497.1999.08168.x

14. Campbell SM, Reeves D, Kontopantelis E, Sibbald B, Roland M. Effects of pay for performance on the quality of primary care in England. N Engl J Med. 2009;361(4):368-378. doi:10.1056/NEJMsa0807651

15. Heath I, Rubinstein A, Stange KC, van Driel ML. Quality in primary health care: a multidimensional approach to complexity. BMJ. 2009;338(apr02 1):b1242. doi:10.1136/bmj. b1242

16. Stange KC, Ferrer RL. The paradox of primary care. Ann Fam Med. 2009;7(4):293-299. doi:10.1370/afm.1023

17. McDonald R, Roland M. Pay for performance in primary care in England and California: comparison of unintended consequences. Ann Fam Med. 2009;7(2):121-127. doi:10.1370/afm.946

18. Wilson T, Holt T, Greenhalgh T. Complexity science: complexity and clinical care. BMJ. 2001;323(7314):685-688. doi:10.1136/ bmj.323.7314.685

19. Sturmberg J. Approaching the future of general practice-how systems thinking might help. Aust Fam Physician. 2004;33(12):1033-1035.

20. Plsek PE, Greenhalgh T. Complexity science: the challenge of complexity in health care. BMJ. 2001;323(7313):625-628. doi:10.1136/ bmj.323.7313.625 
21. Sturmberg JP, Getz L, Stange KC, Upshur R, Mercer S. Beyond multimorbidity. Learning lessons from complexity science. J Eval Clin Pract. in press.

22. Trochim WM, Cabrera DA, Milstein B, Gallagher RS, Leischow SJ. Practical challenges of systems thinking and modeling in public health. Am J Public Health. 2006;96(3):538546. doi:10.2105/AJPH.2005.066001

23. Institute of Medicine Committee on Quality of Health Care in America. Crossing the Quality Chasm: A New Health System for the 21st Century. Washington, DC: National Academy Press; 2001

24. Reynolds CW. Flocks, herds and schools: A distributed behavioral model. Comput Graph. 1987;21(4):25-34. doi:10.1145/37402.37406

25. Franks P, Clancy CM, Nutting PA. Gatekeeping revisited-protecting patients from overtreatment. N Engl J Med. 1992;327(6):424-429. doi:10.1056/NEJM199208063270613

26. Cebul RD, Rebitzer JB, Taylor LJ, Votruba ME. Organizational fragmentation and care quality in the U.S healthcare system. J Econ Perspect. 2008;22(4):93-113. doi:10.1257/jep.22.4.93

27. Donner-Banzhoff N. Solving the diagnostic challenge: A patient-centered approach. Ann Fam Med. 2018;16(4):353-358. doi:10.1370/ afm. 2264

28. Henbest RJ, Stewart M. Patient-centredness in the consultation. 2: does it really make a difference? Fam Pract. 1990;7(1):28-33. doi:10.1093/ fampra/7.1.28

29. Lawson PJ, Flocke SA. Teachable moments for health behavior change: a concept analysis. Patient Educ Couns. 2009;76(1):25-30. doi:10.1016/j.pec.2008.11.002

30. Lin HW, Li CM, Lee YC, Lee LT, Leung KK. Differences in diagnostic approach between family physicians and other specialists in patients with unintentional body weight loss Fam Pract. 1999;16(6):586-590. doi:10.1093/ fampra/16.6.586

31. Stange KC, Etz RS, Gullett H, et al. Metrics for assessing improvements in primary health care. Annu Rev Public Health. 2014;35(1):423-442. doi:10.1146/annurev-publhealth-032013-182438

32. O'Connor PJ, Sperl-Hillen JM, Margolis $\mathrm{KL}$, Kottke TE. Strategies to prioritize clinical options in primary care. Ann Fam Med. 2017;15(1):10-13. doi:10.1370/afm.2027

33. Stange KC. A science of connectedness. Ann Fam Med. 2009;7(5):387-395. doi:10.1370/ afm.990

34. Stange KC. The generalist approach. Ann Fam Med. 2009;7(3):198-203. doi:10.1370/afm.1003

35. Bazemore A, Petterson S, Peterson LE, Bruno R, Chung Y, Phillips RL Jr. Higher primary care physician continuity is associated with lower costs and hospitalizations. Ann Fam Med. 2018;16(6):492-497. doi:10.1370/afm.2308

36. Stange K, Burge F, Haggerty J. RCGP Continuity of Care Toolkit: promoting relational continuity [corrected]. Br J Gen Pract. 2014;64(623):274-275. doi:10.3399/ bjgp14X679957

37. Stewart M, Brown JB, Donner A, et al. The impact of patient-centered care on outcomes. J Fam Pract. 2000;49(9):796-804.
38. Stewart M, Brown JB, Eston WW, McWhinney IR, McWilliam CL, Freeman TR. Patientcentered medicine: transforming the clinical method. 2nd ed. Abingdon, UK: Radcliffe Medical Press; 2003

39. Scott JG, Cohen D, Dicicco-Bloom B, Miller WL, Stange KC, Crabtree BF. Understanding healing relationships in primary care. Ann Fam Med. 2008;6(4):315-322. doi:10.1370/afm.860

40. Wilson MC, Hayward RS, Tunis SR, Bass EB Guyatt G. User's guides to the medical literature: VIII. How to use clinical practice guidelines: $\mathrm{B}$. What are the recommendations and will they help you in caring for your patients? JAMA. 1995;274(20):1630-1632. doi:10.1001/ jama.1995.03530200066040

41. Leopold N, Cooper J, Clancy C. Sustained partnership in primary care. J Fam Pract. 1996;42(2):129-137.

42. Ronis SD, Kleinman LC, Stange KC. A learning loop model of collaborative decision making in chronic illness. Acad Pediatr. 2019;19(5):497503. doi:10.1016/j.acap.2019.04.006

43. Epstein RM, Fiscella K, Lesser CS, Stange KC. Why the nation needs a policy push on patient-centered health care. Health Aff (Millwood). 2010;29(8):1489-1495. doi:10.1377/ hlthaff. 2009.0888

44. Scott JG, Warber SL, Dieppe P, Jones D, Stange KC. Healing journey: a qualitative analysis of the healing experiences of Americans suffering from trauma and illness. BMJ Open. 2017;7(8):e016771. doi:10.1136/bmjopen-2017-016771

45. Sturmberg JP, Cilliers P. Time and the consultation - an argument for a 'certain slowness'. J Eval Clin Pract. 2009;15(5):881-885. doi:10.1111/j.1365-2753.2009.01270.x

46. Heyeres M, McCalman J, Tsey K, Kinchin I. The Complexity of health service integration: a review of reviews. Front Public Health 2016;4:223. doi:10.3389/fpubh.2016.00223

47. Greenhalgh T, Papoutsi C. Studying complexity in health services research: desperately seeking an overdue paradigm shift. BMC Med. 2018;16(1):95. doi:10.1186/s12916-018-1089-4

48. Starfield B, Lemke KW, Herbert R, Pavlovich WD, Anderson G. Comorbidity and the use of primary care and specialist care in the elderly. Ann Fam Med. 2005;3(3):215-222. doi:10.1370/ afm. 307

49. Starfield B. William Pickles Lecture. Primary and specialty care interfaces: the imperative of disease continuity. $\mathrm{Br} \mathrm{J}$ Gen Pract. 2003;53(494):723-729.

50. Fortin M, Soubhi H, Hudon C, Bayliss EA, van den Akker M. Multimorbidity's many challenges. BMJ. 2007;334(7602):1016-1017. doi:10.1136/bmj.39201.463819.2C

51. Baicker K, Chandra A. Medicare spending, the physician workforce, and beneficiaries' quality of care. Health Aff (Millwood). 2004;23(Suppl Web Exclusives):W4-184-97. doi:10.1377/ hlthaff.W4.184

52. Starfield B, Shi L, Macinko J. Contribution of primary care to health systems and health Milbank Q. 2005;83(3):457-502. doi:10.1111/ j.1468-0009.2005.00409.x
53. Orszag P, Rekhi R. The economic case for vertical integration in health care. NEJM Catal. 2020;1(3):CAT.20.0119. doi:10.1056/ CAT.20.0119

54. Thomas P, Meads G, Moustafa A, Nazareth I, Stange KC, Donnelly Hess G. Combined horizontal and vertical integration of care: a goal of practice-based commissioning. Qual Prim Care. 2008;16(6):425-432.

55. De Maeseneer J, van Weel C, Egilman D, Mfenyana K, Kaufman A, Sewankambo N. Strengthening primary care: addressing the disparity between vertical and horizontal investment. Br J Gen Pract. 2008;58(546):3-4 . doi:10.3399/bjgp08X263721

56. Lawn JE, Rohde J, Rifkin S, Were M, Paul VK, Chopra M. Alma-Ata 30 years on: revolutionary, relevant, and time to revitalise. Lancet. 2008;372(9642):917-927. doi:10.1016/S01406736(08)61402-6

57. Henry TL, Petterson S, Phillips RS, Phillips RL Jr, Bazemore A. Comparing comprehensiveness in primary care specialties and their effects on healthcare costs and hospitalizations in medicare beneficiaries. J Gen Intern Med. 2019;34(12):2708-2710. doi:10.1007/s11606019-05338-3

58. Haggerty JL, Beaulieu MD, Pineault R, et al. Comprehensiveness of care from the patient perspective: comparison of primary healthcare evaluation instruments. Healthc Policy 2011;7(Spec Issue):154-166. doi:10.12927/ hcpol.2011.22708

59. Sturmberg JP, Schattner P. Personal doctoring. Its impact on continuity of care as measured by the comprehensiveness of care score. Aust Fam Physician. 2001;30(5):513-518.

60. Bazemore A, Petterson S, Peterson LE, Phillips RL Jr. More comprehensive care among family physicians is associated with lower costs and fewer hospitalizations. Ann Fam Med. 2015;13(3):206-213. doi:10.1370/afm.1787

61. Sturmberg JP. Systems and complexity thinking in general practice: part 1 - clinical application. Aust Fam Physician. 2007;36(3):170-173. 